\title{
Knowledge, Perception and Willingness to Pay for Cord Blood Banking: A Pilot Study
}

Bavani Naido Munisamy Naidu, Sheiladevi Sukumaran \& Sharmanee Thiagarajah

To Link this Article: http://dx.doi.org/10.6007/IJARBSS/v11-i10/11489

DOI:10.6007/IJARBSS/v11-i10/11489

Received: 02 August 2021, Revised: 29 August 2021, Accepted: 18 September 2021

Published Online: 11 October 2021

In-Text Citation: (Naidu et al., 2021)

To Cite this Article: Naidu, B. N. M., Sukumaran, S., \& Thiagarajah, S. (2021). Knowledge, Perception and Willingness to Pay for Cord Blood Banking: A Pilot Study. International Journal of Academic Research in Business and Social Sciences, 11(10), $1107-1120$.

Copyright: (C) 2021 The Author(s)

Published by Human Resource Management Academic Research Society (www.hrmars.com)

This article is published under the Creative Commons Attribution (CC BY 4.0) license. Anyone may reproduce, distribute, translate and create derivative works of this article (for both commercial and non-commercial purposes), subject to full attribution to the original publication and authors. The full terms of this license may be seen at: http://creativecommons.org/licences/by/4.0/legalcode

Vol. 11, No. 10, 2021, Pg. 1116 - 1120

Full Terms \& Conditions of access and use can be found at http://hrmars.com/index.php/pages/detail/publication-ethics 


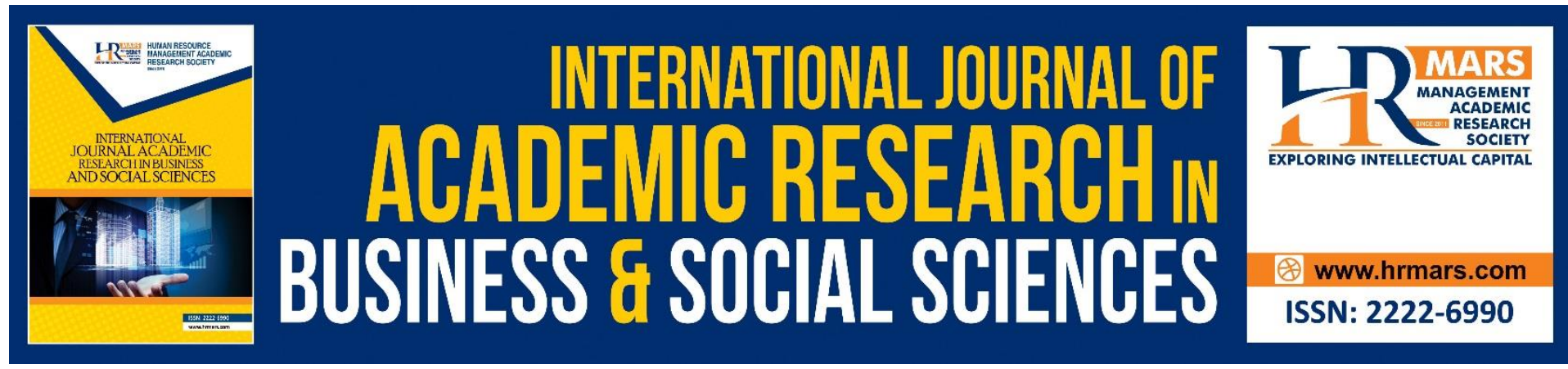

\title{
Knowledge, Perception and Willingness to Pay for Cord Blood Banking: A Pilot Study
}

\author{
Bavani Naido Munisamy Naidu, Sheiladevi Sukumaran \& \\ Sharmanee Thiagarajah
}

Faculty of Medicine and Health Science, UCSI University, Jalan Menara Gading 1, 56000 Kuala Lumpur, Malaysia

\begin{abstract}
Umbilical cord blood was once a waste product. Now, years after the first successful cord blood transplant, it is an alternative source of hematopoietic stem and progenitor cells, compared to bone marrow and peripheral blood, which can cure children and adults from malignant and non-malignant diseases. The aim of this research was to assess the knowledge and perception for cord blood banking among Malaysian pregnant women and also ascertain the willingness to pay. Population selected for this study is Malaysian pregnant women who visited the Mom \& Baby Expo in Midvalley, Kuala Lumpur. 43\% of the respondents aged between 18-25 years old with good education background, good job and total household income of more than RM 5,000. 89\% of respondents were at the 1st trimester and 2 nd trimester of pregnancy. Approximately about $47 \%$ of respondent had some knowledge of cord blood banking. Almost $90 \%$ of respondents agreed that storing the cord blood will be useful for future treatment. Approximately $54 \%$ of respondents agree that most of the information about cord blood banking were obtained from medical health care professional. The level of knowledge correlate with the education background, higher education level showed more knowledge. Majority of $93 \%$ have not stored their children's umbilical cord blood before. Based on the perception, $41 \%$ of the respondents thought its unnecessary to store cord blood despite knowing it is not harmful for mother or baby. About $51 \%$ thinks that the price of the cord blood is very expensive. About $81 \%$ of respondent agree that the maximum benefit can be gained from storing the cord blood is to baby itself. $49 \%$ respondents agreed that about $25 \%$ and below possible chances that a child's cord blood could benefit for his siblings. After explanation, about $41 \%$ were sure to store cord blood compared to $68 \%$ prior to it. Approximately $78 \%$ prefer to store cord blood in public bank because no fee charged. Almost $50 \%$ respondents are not willing to pay the cost approximately $\mathrm{RM} 3,000$. The survey also found that the most affordable price that they can pay is between RM 500- RM 1,000. Awareness is present but detailed knowledge regarding its exact benefits and advantages still unclear. Public education should be done by everyone instead of only medical personnel. A reduction in the cost of umbilical cord blood collection and preservation and more knowledge would motivate the public to store cord blood. More campaigns and awareness programs are necessary especially among the younger generation, the future parents.
\end{abstract}




\section{Keywords: Knowledge, Perception, Willingness, Cord Blood Banking}

\section{Introduction}

This research is to assess the knowledge and perception for cord blood banking (CBB) among Malaysian pregnant women and to assess the willingness to pay for cord blood banking among Malaysian pregnant women. Until to date there is no much survey or data compilation on the knowledge and perception towards CBB particularly in Malaysian society. This study is designed to determine a small population of Malaysia's knowledge and perception about CBB. Currently there is a lack of researchers and policy makers in considering how this new technology on CBB could contribute in improving health today. There are not many studies carried out to determine the level the knowledge and willingness to pay among Malaysia pregnant women regarding CBB. This study surveyed the level of awareness and with better knowledge and understanding about CBB, would help to identify the reasons for the lack interest among public to donate umbilical cord blood (UCB).

UCB was once only a waste product which was disposed after the birth of a baby. Lately, after successful cord blood (CB) transplant in 1988, some parents worldwide have developed interest and seek for information regarding CBB (Louiza et al., 2012; Waller-Wise, 2012). CB is an potential source of hematopoietic and progenitor stem cells, in comparison to other sources of stem cells such as bone marrow and peripheral blood, which can be therapeutic to children and adults from malignant, non-malignant and familial or genetically inherited metabolic diseases (Butler and Menitove, 2011, Lee, 2014; Louiza et al., 2014). Since 1988 , after the first successful UCB transplantation by Gluckmann in Paris, the use of CB stem cells has raised. The use of this alternative hematopoietic source has many advantages for donors and the recipients too. Advantages of $C B$ are such as prompt availability, donors are free from risk of anesthesia, low risk of transmissible infections and lower risk of posttransplant immune response and easy manner of collection with little risk to mother or new born (Parco et al., 2013).

There are two types of banks that stores CB. One of it is known as the public banks which collect donated $C B$ for research or for use by anyone who may need it. This service is free in Malaysia. The other type of bank is private bank which stores CB for personal use by the family. There is a fee associated with this service and people with family history of diseases, usually opt for this choice as they can be treated with autologous or allogeneic transplants (Louiza et al., 2014). Blood sample that is obtained from baby's umbilical cord blood is known as UCB or CB. The sample collection of CB is done upon the baby's birth. Collection of $C B$ doesn't either disrupt birth plans that has been made or harm the mother and baby. After delivery, normally the doctor or midwife has to clamp the umbilical cord and cut it off. Collection of UCB is a very easy method where a needle provided in the collection kit is inserted into the cord to collect the remaining blood in the cord before the placenta is delivered (Armson, 2005). The sample obtained, is sealed in a bag and labelled with personal details and sent to the bank. CB is an excellent and rich source of proliferative stem cells, including hematopoietic stem and progenitor cells which could be used to treat various diseases currently (Armson, 2005; Louiza et al., 2014).

$C B$ has been successfully used in treating malignant and non-malignant hematological disorder, immunological deficits, and inherited metabolic disorders and genetic disorders (Armson, 2005; Butler and Menivote, 2011). CB is currently used as an alternative to bone marrow and peripheral stem cells in the use of treating children and adults who suffers from malignant and non-malignant disorders (Armson, 2005). Besides providing a rich source of 
hematopoietic stem cells, there are many advantages in using CB. Advantages mentioned are such as prompt and surplus accessibility with no risk of anesthesia or pain for mother and baby, low risk of infection transmissions and decreased risk of immune incompatibility such as graft-versus host disease (GVHD) upon stem cell transplant. Limitations in CB transplantation are the insufficient amount of stem cells dose to adequately target the recipients, risk of transferring genetically abnormal stem cells and delayed engraftment which means new blood forming cells growth is slow (Armson, 2005; Waller-Wise, 2012). Inadequate stem cell dose obtained from single collection of UCB was a failure in treating heavy body mass patients. In contrary, prior to bone marrow (BM) transplantation, the volume of BM extracted is calculated based on recipient's body mass. Hence, double unit of $\mathrm{CB}$ are used and ex-vivo expansion is carried out to increase the infused stem cells to overcome low stem cells content from single UCB collection. Interosseous injections were done to overcome delay in new blood forming cells growth, engraftment (Lee, 2014). Currently, commonly used method to prevent limitations of stem cell dose is double CB transplantation (Lee, 2014).

A cord blood bank (CBB) is where $C B$ are stored for future use after samples obtained from baby's umbilical cord. In the past few decades, after multiple successful CB transplantation and encouraging treatment results, usage of $C B$ has become vast and $C B$ banking has been widespread all over the world. There are two types of CBB available: private (or family) and public. Public CBB are accessible for all donors and recipients (Lee, 2014). Public CBB obtains CB samples after receiving consent from the parents mainly for altruistic reason. The $C B$ units stored in the public bank are kept for later use for the public and for research purposes as well. The CB samples are registered based on quantity, tissue types, number of cells and donor's health history and infection status. Prior to transplantation or research, information is searched and accessed by healthcare personals (Lee, 2014). Public CBB does not reserve the $C B$ units for the specific family that has donated the $C B$ but they are available to be used by general public (Waller-Wise, 2012; Petrini, 2014). Private CBB stores $\mathrm{CB}$ obtained individually for the use of the infant or their own family under the guardian of the infant's parents. The samples obtained are charged to be kept and maintained in private banks. These samples are only used for infant donor or related family members, based on the guardians or parents wish. These samples are not allowed to be used for researches and not available for the public use (Lee, 2014; Petrini, 2014).

The stem cells obtained from $\mathrm{CB}$ has lesser risks of rejection after transplantation compared to bone marrow as they produce lesser immune cells. There are reports showing the rate of rejection of $C B$ is half the rate compared to $B M$ transplantation. There are many advantages of using $\mathrm{CB}$ stem cells over BM stem cells for transplants as mentioned above. For BM transplants, it takes a long period of time to find a specific match and the process of sample collection is tedious as there are risks of anesthesia, post collection pain and donor needs to be hospitalized (Armson, 2005). Whereas the collection of CB is not painful and no anesthesia required can be done before or after the placenta expulsion. Risks on infection via $\mathrm{CB}$ is less as the history screening eliminates collection of UCB from mothers who has or history of human immunodeficiency virus, cytomegalovirus, syphilis, group B streptococcus, genital herpes and prolonged (more than 18hours) rupture of membrane and chorioamnionitis (Waller-Wise, 2012). Stem cells have the potency to differentiate into any specialized cells, self- renewal and can divide further via mitosis to produce higher number of stem cells (Abotalib, 2013). Stem cells are divided in two types embryonic stem cells and adult stem cells. Embryonic stem cells are obtained from inner cell mass of blastocysts which 
differentiates into ectoderm, endoderm and mesoderm, whereas adult stem cells are found in various tissues such as bone marrow, adipose tissues, peripheral blood and many other tissues. Commonly stem cells treated illness are malignancies, blood disorders, congenital or familial metabolic disorders and reduced immunity states. Lymphoma and leukemia are malignancies that are successfully treated with stem cells. Various blood or hematological disorders can be treated with stem cells (Armson, 2005; Waller-Wise, 2012). Researchers are still working on and investigating and studying variable applications of stem cells to treat more diseases. In 2006, there were researches reported on usage of stem cells to treat autoimmune diseases and in 2007, there reports of stem cells used to treat myocardial infarcts, cerebralvascular assaults, liver disorders, diabetes mellitus and brain and spinal cord injuries (WallerWise, 2012). Most of the CB transplants which are obtained from unrelated donors and rarely suitability or match are a problem when in comparison to related donor. Lately, with the broad usage and demand of transplantation, unrelated CB transplantations have been used widely for those patients who lack matching donor (McKenna and Sheth, 2011).

\section{Materials and Methods}

This study was a cross sectional survey with questionnaire. Sample size calculation was not based on a statistical but on a pragmatic approach. For the scope of this study the aim was to recruit at least 100 participants. Pregnant women who visited the Mom \& Baby Expo in Midvalley Exhibition Centre Kuala Lumpur. Sampling method was based on inclusion and exclusion criteria's. Pregnant women who visited the study location for shopping or visit were identified and screened based on inclusion and exclusion criteria. Patients who fulfilled the inclusion and exclusion criteria were informed about the study and if they agreed to participate, they were given consent form, patient information form and case report form to be filled. Questionnaire consist of questions assessing demographics, awareness and knowledge regarding $C B$ banking, perception concerning $C B B$ and willingness to pay for $C B B$. There were 9 questions regarding demographics, 10 questions assessing knowledge and awareness, 14 questions to understand perception on CBB and 4 questions to study the willingness to pay for CBB. Participation in the survey was voluntary and patients were allowed to change their mind at any time and withdraw from the study without giving a reason if they intended to. This research was analysis by using SPSS version 21 . The nature of the research is more on exploratory study therefore only descriptive analysis were included. There are three main research questions need to been answered. The first part of these data findings will cover the area of respondent demography variables such as gender, age and academic qualification. Second part will answer all the three research questions.

\section{Analysis and Finding}

Majority of the respondents aged between $18-25$ years old were $43 \%$ and only $2 \%$ from oldest group age which was more than 50 . Almost $21 \%$ of the respondents were Malay, $45 \%$ were Chinese and $27 \%$ were Indians. The academic qualification data revealed that the entire respondent had some basic education and minimum of primary education (1\%). This was followed by $8 \%$ of the respondents holding a secondary school certificates such as PMR and SPM, and majority (68\%) were having at least a bachelor's degree. Interestingly, $47 \%$ of respondent were pregnant at the $1^{\text {st }}$ trimester and followed by $41 \%$ at $2^{\text {nd }}$ trimester. In terms of personal income trend, it was found that $22 \%$ of respondents had income of less than RM 2,000 or equivalent and this could be due to the about $32 \%$ of respondent were students. About $29 \%$ of respondents had personal income within RM 2,000 to RM 4,000 and $39 \%$ of the 
mothers earned between RM 4,001 to RM 6,000. While majority overall household income showed that $85 \%$ of respondent obtained minimum of RM 5,001 and above. High household income could be presumed due to good education background hence a good job. About $50 \%$ of respondents were actually carrying their second child, $28 \%$ were carrying their third child and a minority of 6 of them were pregnant for the first time.

Chi Square Test was conducted to determine the relationship between demographic factors and knowledge level on CBB. Chi-square tests showed knowledge level on CBB associate significantly ( $p$ value $<0.05$ ) between employment status and stage of pregnancy whereas associate highly significant ( $p$ value $<0.01$ ) with personal income. Self-employed respondents, tend to have better knowledge level on CBB. Pregnant women in 3rd trimester pertained better knowledge level on CBB in comparison to 1st and 2nd trimester pregnant women. Respondents who were earning more than RM10000 per month were more curious and keener to know more on knowledge level on CBB. Other demographic factors such as age, ethnicity and education showed no association with knowledge level on CBB. 
INTERNATIONAL JOURNAL OF ACADEMIC RESEARCH IN BUSINESS AND SOCIAL SCIENCES Vol. 11, No. 10, 2021, E-ISSN: 2222-6990 @ 2021 HRMARS

TABLE 1: Correlation between the Demographic Factors and Knowledge Level on Cord Blood Banking (CBB).

\begin{tabular}{|c|c|c|c|c|c|c|}
\hline & Demographic factor & Mean & $\begin{array}{l}\text { Std. } \\
\text { Deviation }\end{array}$ & $\begin{array}{l}\text { Pearson } \\
\text { Square }\end{array}$ & Chi- & $p$ value \\
\hline \multirow[t]{6}{*}{1} & Age & & & & & \\
\hline & $18-25$ & 0.814 & 1.052 & 21.715 & & 0.153 \\
\hline & $26-30$ & 1.000 & 0.943 & & & \\
\hline & $31-35$ & 1.210 & 1.031 & & & \\
\hline & $36-40$ & 1.647 & 0.931 & & & \\
\hline & $>40$ & 1.500 & 0.707 & & & \\
\hline
\end{tabular}

2 Ethnicity

$\begin{array}{llccc}\text { Malay } & .714 & 0.717 & 12.228 & 0.428 \\ \text { Chinese } & 1.044 & 0.999 & & \\ \text { Indian } & 1.143 & 1.118 & & \\ \text { Others } & 1.080 & 1.464 & & \end{array}$

3 Education

$\begin{array}{lllll}\text { Non formal } & - & 0.000 & 4.246 & .979 \\ \text { Primary } & 1 & 1.000 & \\ \text { Secondary } & 8 & 1.074 & \\ \text { Tertiary } & 68 & 1.173 & \\ \text { Postgraduate } & 23 & & \end{array}$

4. Employment

\begin{tabular}{lllll} 
Public sector & \multicolumn{1}{c}{0.935} & \multicolumn{1}{c}{.681} & 29.247 & $.022 *$ \\
employee & & 1.213 & .987 & \\
Private & sector & & 1.414 & \\
employee & 2.000 & 1.154 & \\
Self-employee & .667 & 1.007 & \\
Unemployed & .781 & & \\
Student & & &
\end{tabular}

5. Pregnancy Stage

$\begin{array}{lllll} & & 1.144 & 26.349 & .049 * \\ 1^{\text {st }} \text { trimester } & 1.976 & 0.946 & & \\ 2^{\text {nd }} \text { trimester } & 1.171 & 0.775 & & \\ 3^{\text {rd }} \text { trimester } & 4.000 & & & \\ \text { Personal income } & & & & \\ <2000 & 0.389 & 0.777 & 62.121 & \\ 2000-4000 & 0.966 & 0.778 & & \\ 4001-6000 & 1.282 & 0.731 & & \\ 6001-8000 & 1.889 & 1.050 & & \\ >10000 & 4.000 & 1.054 & & \end{array}$


p-value less than 0.05 (typically $\leq 0.05$ )* is statistically significant; $p$-value less than 0.01 (typically $\leq 0.01)^{* *}$ is statistically highly significant..

About $76 \%$ of respondent, who are mostly well educated had some knowledge of CBB. From the pie chart, it is clearly indicated that majority of respondent had some basic knowledge or awareness regarding the CBB. Most of the respondent, $40 \%$ agreed that storing CB will be useful for future treatment of cancer. About $25 \%$ respondents agreed that storing $C B$ will be useful for diabetes mellitus treatment and similar to future treatment of osteoarthritis. Only $10 \%$ respondents said there is relationship between CB storage and its usage for heart disease treatment in the future. Only $10 \%$ of respondents were unaware of the benefits of $\mathrm{CBB}$ in future. It clearly indicates the insufficiency of awareness campaigns to heighten public's knowledge on CBB in Malaysia and it can be proved by the survey data where about $48 \%$ agreed the awareness campaign concerning CBB is limited. The data shows that Malaysians still lack knowledge on CBB services and benefits. Approximately 54\% respondents agreed that most of the information about CBB were obtained from medical health care professionals. The respondents agreed that very limited advertisement about CBB were advertised in television. However, gaining information from friends also play significant role in disseminating news concerning CBB. it shows that about more than $36 \%$ respondents had a little knowledge about CBB.

Only $3 \%$ respondent had strong knowledge on CB storage. Interestingly the percentages of respondent with knowledge were fewer than respondents with less knowledge. $34 \%$ of respondents had no knowledge at all. From the survey conducted level of knowledge correlates with the education background. A few of respondents with post graduate level of education had good and strong knowledge regarding CBB, whereas remaining post graduates and most respondents with tertiary education had little or some knowledge concerning $C B$. From the figure above, it is clearly seen that about $36 \%$ respondent had difficulty to understand the CBB information due to language barrier. Language barrier could be due to the terms used which were very medical based. Another hindering factor is the education gap. The educated group of people tend to easily understand the need of CBB procedures and benefits. Approximately $21 \%$ of respondents mentioned that lack of information regarding the CBB was one the obstruction in spreading knowledge concerning CBB. shows that $93 \%$ have not stored their children's CB before. This is mainly due to the lack of knowledge and knowing the benefits and perks of storing $C B$. Only $7 \%$ of total respondents have stored in $\mathrm{CBB}$ previously and private banks were chosen. Based on the survey, those with personal income of RM 6,000 to RM 8,000 are those who chose to store CB. Figure 4.8, shows that about $53 \%$ respondents have not seen any of their relative or friends never benefited from storing $\mathrm{CB}$ or treatment using stem cells before. Only $10 \%$ of respondents have seen their relatives and friends actually benefited from $C B$ storage.

From the knowledge level, it can be assumed that CBB is unfamiliar among the Malaysians. Based on the perception, most of the respondents $41 \%$ prefer not necessary to store CB. About $30 \%$ were sceptical whether it was necessary to store or not to store the CB - Remaining $29 \%$ of respondents were keen to store $C B B$. About $68 \%$ respondents do not prefer to store $\mathrm{CB}$ due to the price of $\mathrm{CBB}$ storage which is expensive as shown in the figure above. Most of the respondents are not aware of public bank availability as lack of knowledge and poor information available for public concerning CBB options. About $17 \%$ were sceptical if their children or family members would really benefit from CBB. Roughly around $9 \%$ of respondents assumed that $\mathrm{CBB}$ is just not necessary probably because they have good family history. Another $4 \%$ were not keen for donating their family CB for future researches because 
worried that their children's CB could be misused. It shows about $44 \%$ respondents feel that it is not necessary to store $C B$ for all their children. Whereas $31 \%$ of respondent were totally unsure if it was necessary to store $C B$. Though expensive and not affordable $25 \%$ of respondents feel it is necessary to store $C B$. interestingly, despite limited knowledge on $C B$, about $73 \%$ of respondent were aware that CB storage is not harmful to either mother or the baby. shows about $81 \%$ of respondent agree that the maximum benefit can be gained from storing the $C B$ is to baby itself. According to respondents, benefit to other family members is not as beneficial as to baby itself. They should be educated regarding autoimmune disorders and genetic disorders where own blood would not be beneficial. above about 49 respondents do agree that about $25 \%$ possible chances that a child could benefit from his or her own CB. However, the percentage said the maximum benefit a child could benefit just from his or her own $C B$ is 6 respondents.

About 69 of respondents agreed that storing CB possibly could benefit own parents by $25 \%$ of chances as shown in the pie chart above. Only 3 respondents agreed that CB storage could benefit parents by $76 \%$ and above chances. The similar trend was also found among the siblings who have possible chance to gain benefit from his or her sibling's CB. About 49 respondents do agree that below $25 \%$ possible chances that a child could benefit from his or her sibling's CB. Concerning benefit of CB stored for sibling and parents' remains unclear in this study as most of the respondents have not stored $C B$ before, therefore poor knowledge. Almost $68 \%$ were unsure to store $C B$ as shown by figure 4.17 . However, for those who are interested to store their option is only two which are either public bank or private bank. About $21 \%$ respondents prefer private bank rather than public bank even though CBB storage is expensive. Respondents probably feel that $C B$ that has been stored privately are well preserved and kept safely for future use.

Public banks collect donated CB for research or for use by public who may need it. There is usually no charge associated with this service and they are available in Hospital Kuala Lumpur/ University Malaya Medical Centre. However, private bank store CB for personal use of the family. This service is provided at a fee by companies such as Cryocord and Stemlife. After reading the scenario from table 4.2 , about $41 \%$ were sure to store $C B$. However about $26 \%$ of respondent are still in ambiguity about the benefits of CBB. Respondents lack on information and they should be educated more concerning $C B$ and the storage bank services that is available. After reading the scenario, among the 41 respondents who were keen to store $C B, 63 \%(n=26)$ of them prefer public bank and remaining $37 \%(n=15)$ opted for private banking as seen in figure 4.19 . The main reason, $69 \%(n=18)$ opted for storing in public bank because it is too costly to store in private bank. Again the expenses are the main reason of why Malaysians hesitate to store CB . Some, $15 \%(n=4)$ thought that donating CB to public bank could increase the pool and be beneficial for others. Respectively $8 \%(n=2)$ assumed that their child might not need own CB and therefore storing public bank would be free of charge and could be used for others and the other remaining $8 \%(n=2)$ prefer donating to public bank for future research uses. Among the respondents who opted for private banking, $13 \%(n=2)$ respondents agreed storing $C B$ is a kind of investment for their offspring in future and another $13 \%(n=2)$ assumed that own blood that is stored is safer in comparison to blood acquired from donor's pool.

Only $7 \%(n=1)$ agreed that storing in private bank is not too costly and acceptable and another $7 \%(n=1)$ prefer to store CB in private bank because sceptically thinking that in public bank the pool of blood is easily accessible and can be misused. About $40 \%(n=6)$ trust that the storage quality and the method of stem cell preservation in private bank are better in 
comparison to public bank concerning the fee charged. About $20 \%(n=3)$ chose to store CB in private bank due to avoid the guilt of overlooking the storage of $C B$ and if in case there's need in future. About $50 \%$ respondents are not willing to pay the cost as minimum as RM 3,000 for single delivery and a yearly storage payment of RM 250. Respondents who were willing to pay for the current market charges of CB storage were about $27 \%$ of them and $23 \%$ of them were uncertain. The survey also found that the most affordable price that respondents can pay for CB storage is between RM 500- RM 1,000. 80\% respondents think that RM 500 to 1,000 is an affordable range. Some of the respondents who are with higher monthly income does not mind a higher fee which within RM 1,001 to RM 1,500. None of the respondents preferred fees more than RM 1,500. About $51 \%$ of respondents agree to pay for CB storage for duration between $0-5$ years. Only $10 \%$ of respondents are willing to pay for more than 21 years. Roughly about $21 \%$ are willing to pay for duration of 6 to 10 years for CB storage and $7 \%$ of respondents do not mind paying for 11 to 15 years assuming it is an investment for their children. Respondents with household income of more than RM 20, 000 are willing to pay for long term as it would be an investment for their children.

\section{Discussion}

There is a huge controversy regarding CBB worldwide. Choosing to store in a public or private bank is a great debatable topic. Over the recent years, quite a huge number of studies have been conducted focusing on public's knowledge, habits, and social backgrounds towards CBB (Salvaterra et al, 2010). The aim of this survey conducted was to assess the extent of knowledge regarding $C B$, mindset regarding $C B$ and willingness to pay for $C B$ among the Malaysian population. The individuals chosen to be surveyed were parent to be in near future, pregnant women. Most of the survey participants were in the age group of 18 years old to 25 years old with good education background. Living quality has been heightened with good education and job. Average income of most of the participants varied form RM 2,000 to RM 6,000 and about $85 \%$ of respondents had total household income of more than RM 5,000.

Respondents with good income were keen to take part in this survey as they do not mind paying for the future of their children and their high education background make them curious and keen to explore more knowledge concerning UCB as it could benefit their children. Most of the respondents who attended the expo were from younger age group and well educated and they are aware of the good deals they can expect from expo for their future baby. Respondents were mostly also from first and second trimester as their pregnancy not too big and they wouldn't feel tired as in third trimester to shop in the expo. Most of the respondents were not carrying their first child. Therefore, they are well experienced that good branded baby products can be attained from the expo for reasonable price.

Among pregnant women participated in this study, most of them have heard about CBB due to their good education background where they could attain some information from reading magazines, browsing the internet or from communicating with their friends and family. However, their awareness regarding CBB still needs to be improvised. Stem cells, which are richly found in UCB are vigorously studied and it seems to be beneficial to treat and overcome many diseases such as diabetes mellitus, malignancies, heart related diseases, osteoarthritis and many more. However, most of the stem cells benefits are still on study and clinical trials. In view of indefinite benefit and ongoing studies regarding CB and stem cells, public mostly are sceptical of the usage of them in the near future. More studies need to be done and advantages of $C B B$ and use of stems cells should be proven to make public realize that it is beneficial to store CB. Evidence based knowledge would be beneficial especially 
among educated group. Awareness campaigns on UCB perks is necessary to heighten the public knowledge on $\mathrm{CBB}$, especially among the younger generation who will be parents soon. Most of the pregnant women and their partners gain some knowledge regarding CBB from their medical health care professionals during their antenatal check-ups and prior to delivery. Medical health care professionals are the most reliable personnel in educating pregnant mothers and soon to be parents with unbiased explanation regarding $C B$ and stem cells (Parco et al., 2013). Private bank organizes campaigns especially in mother and baby expo and advertise in parenting magazines whereas no much information disseminated regarding government bank.

Mass media has been a non-reliable source to disseminate benefits of CBB and its possible usage in future. Mass media especially internet and newspapers should advertise and spread more information regarding CBB as mass media is a good source for heightening public's knowledge, especially the younger generation who will be having their own family soon. However, in a study conducted in Europe comprising France, Germany, Italy, Spain, and the United Kingdom showed more than $50 \%$ of pregnant women whom participated in the study gained knowledge concerning UCB through mass media (Katz et al., 2010). Usage of sophisticated language or medical jargons could be a problem in educating the public. Simple, meaningful language should be used. Educated group of people and professionals would interpret and understand benefits of CBB easily compared to vice versa. More information on CBB and stem cells benefits, in simple language would be an excellent method to target all layers of the social community. Without adequate knowledge regarding the CBB most of future parents are interested to store $\mathrm{CB}$; however, they should be educated more in terms of storage options, economic issues and to what extent is the $C B$ beneficial at current moment.

Survey conducted showed the majority of participants have not stored CB previously and majority was unsure if any of their friends or relatives whom actually benefited from $C B$. Lack of studies on definite benefits of $C B$ in the current era results in poor usage of $C B$ and knowledge. Perception of soon to be parents concerning storage of CB among Malaysians is still a huge problem. Despite some knowledge and understanding regarding $C B$, most of them would choose not to store the $\mathrm{CB}$ due to the cost. In average, the payment for initiation of $\mathrm{CB}$ collection and storage and annual payment for preservation is expensive. In research conducted in Italy by Parco et al in 2013 showed that low economic situation, poor knowledge and language barrier in understanding $C B$ and stem cells benefit hindered the population, especially non-Italian's form choosing CBB. The Greek citizens gained their information regarding CB advertising campaigns organized by both governmental and non-governmental (Louiza et al., 2014).

Good understanding among public regarding the collection method of $C B$ which is simple and harmless for both mother and baby. The collection of cord blood is done from the umbilical cord just after delivery from the cord attached to the placenta. This method does not induce any pain or need of any blood pricking from mother or baby. Future mothers should be explained about this information mainly by the medical personnel such as doctors, midwifes and nurses during antenatal check-up and antenatal classes as it would motivate them to store CB instead of being sceptical that it might induce pain and therefore avoid it.

There is a huge controversy about storing blood for 1 child or for all children. Concerning who could benefit the most from stored CB remains a taboo still. So far, the advantage of using the patient's own cells is that there is no risk of autoimmune rejection where, the recipient's body will not reject his own transplanted cells. In certain conditions due to similar 
blood group and genetics, siblings and family members may not undergo autoimmune rejection compared to anonymous donors. There is possibility of parents thinking of being bias because storing only one child's CB instead of all children. Parents would feel guilty in near future if they store one child's blood and when the other sibling in need and it does not match. In order to avoid biasness and guilt, parents can opt for storing in public bank as it would increase the donor's pool and possibility of matching would be easier when there is increased availability of CB in the bank. However, there are some downsides in using own genetic material which is, in cases of genetic diseases, the own stored stem cells will not be able to cure the disease or benefit as the stored stem cells carries the same disease, due to same genetics. One the disease where CB is currently used is leukaemia among children but recent studies suggested that using their own $C B$ will not be an effective treatment as the precursor of the cancer are present in the stored CB. In these cases, a baby's own blood cannot be used for himself or herself and the sibling's CB could be beneficial but remains a doubt when concerning match and autoimmune rejection.

Parents should be educated that not necessarily when their children's CB is preserved it definitely can be used for their child or children or family members in any diseases. The possibility or autoimmune rejection, genetic disorder and other pitfalls explanation should be given unbiased. Unrealistic hope in parents should be avoided. This phenomenon could be overcome by educating the parents regarding the cryopreservation methods and possibility of autoimmune rejection. Public tend to assume that if $C B$ is collected from their child and reserved, it would certainly be compatible and could be definitely transplanted, whereas CB from anonymous donors may not be suitable at all (Palten and Dudenhausen, 2010). After brief explanation and educating future mothers regarding the costs and function of public and private banks for $C B$ banking, most of them prefer public bank mainly the reason being the price. However, there are still public who would choose private banking as their mentality would be good investment for children in future and believing private bank offers better storage methods and are more highly equipped. CB storage in public bank can benefit for future researches and it could be a help to anyone who need it for their treatment. However, some may worry that storing in a public bank gives an easy access to the $\mathrm{CB}$ and their genetic materials and it could be misused. Public bank should organize campaigns around as done by the private banks in order to explain to future parents and public about their availability of service, preservation method and the benefits of CBB as well.

Economic background and financial status remain as a major factor hindering public from opting from private $\mathrm{CBB}$. If the cost remains low, most people would not hesitate to opt for private CBB keeping in mind the benefits and advantages it could provide for their children and family. Public banks can be used to store $C B$ in view or economic constrains for public. Blood stored in public bank could benefit for own use, everyone in need and could be helpful for future studies as well. Public should be educated as well, that not necessarily CB stored in public banks are not preserved in good conditions. Responds and interest in CB storage improved after a brief explanation provided in both public and private banking services. Prior to explanation of the facilities available, most respondents were unsure of which bank would be their preference due to poor knowledge and information concerning CBB services. Most of the respondents prefer public banking as it is too costly to store in private banks. Similar to data obtained in this study, most of the Canadian women chose to donate and store CB in public bank due to economical constrains (Conrad et al., 2003). Some of the respondents also thought that public bank storage would be beneficial for others and also for research use instead of private banking which CB will be kept for personal use only and the chances of 
usage is low. Most of the respondent willing to pay between the ranges of RM 500 till RM 1,000 as with more children, they have to plan for future savings and needs as well. In Malaysia, lack of awareness campaigns and information regarding CB is the major problem. More campaigns, talks, advertisements should be initiated to propagate the benefits of CBB in order to increase the awareness. Besides medical personals, ministry of health should play a major role in educating the public. Government health clinics and Klinik1 Malaysia which are well dispersed throughout Malaysia should also take some steps in propagating information regarding CBB as it would be able to educate both rural and urban parents and future parents.

\section{Conclusion}

In conclusion, the younger generation of Malaysian parents are well educated with good monthly and household income and they are aware of CBB. Awareness is present but detailed knowledge regarding its exact benefits and advantages are poorly understood and misleading. Perception concerning CBB should be improvised and this can be attained with good knowledge on CBB. More clinical researches should be carried out vastly to provide good statistics outcomes in the upcoming years regarding stem cell therapy. More experiments and clinical trials should be carried out to ensure safety and beneficial use of stem cells which are abundantly found in CB.

\section{Acknowledgement}

The authors would like to thank the UCSI University for the access support to send questionnaires online.

\section{Corresponding Author}

Sharmanee Thiagarajah

Faculty of Medicine and Health Science, UCSI University, Jalan Menara Gading 1, 56000 Kuala Lumpur, Malaysia

Email: sharmanee@ucsiuniversity.edu.my

\section{References}

Abotalib, Z. (2013). Importance of cord blood stem cells in regenerative medicine. Saudi Journal of Biological Science, 12, 1-34.

Armson, B. A. (2005). Umbilical cord blood banking: implications for perinatal care providers. Journal of Obstetic Gynaecology Cancer, 27(3), 263-90.

Butler, M., \& Menitove, J. (2011). Umbilical cord blood banking: an update. Journal of Assist Reproductive Genetics, 28(8), 669-676.

Katz, G., Mills, A., Garcia, J., Hooper, K., McGuckin, C., Platz, A., Rebulla, P., Salvaterra, E.,

Schmidt, A., \& Torrabadella, M. (2010). Banking cord blood stem cells: attitude and knowledge of pregnant women in five European countries. Transfusion, 51(3), 578-586.

Lee, Y. (2014). Clinical utilization of cord blood over human health: experience of stem cell transplantation and cell therapy using cord blood in Korea. Korean Journal of Pediatric, 57(3), 110.

Mckenna, D., Sheth, J. (2011). Umbilical cord blood: current status \& promise for the future. Indian Journal of Medical Respiration. 134, 261-269.

Palten, P., \& Dudenhausen, J. (2010). A great lack of knowledge regarding umbilical cord blood banking among pregnant women in Berlin, Germany. Journal of Perinatal Medicine, 
38(6), 651-657.

Parco, S., Vascotto, F., \& Visconti, P. (2013). Public Banking of Umbilical Cord Blood or Storage in a Private Bank: Testing Social and Ethical Policy in Northeastern Italy. Journal of Blood Medicine, 4, 23-29.

Petrini, C. (2014). Umbilical Cord Blood Banking: From Personal Donation to International Public Registries to Global Bioeconomy. Journal of Blood Medicine, 5, 87-97.

Salvaterra, E., Casati, S., Bottardi, S., Brizzolara, A., Calistri, D., Cofano, R., Folliero, E., Lalatta, F., Maffioletti, C., Negri, M., \& Rebulla, P. (2010). An analysis of decision making in cord blood donation through a participatory approach. Journal of Transfusion Apher Science, 42(3), 299-305.

Waller-Wise, R. (2011). Umbilical cord blood banking: implications for perinatal care providers. Journal of Perinatal Education, 20(1), 54-60. 